\title{
NOITES DENTRO DA PÓS-MODENIDADE: UMA LEITURA DE DOIS ROMANCES BRASILEIROS CONTEMPORÂNEOS
}

\section{NIGHTS INTO THE POSTMODERNITY: A READING OF TWO CONTEMPORARY BRAZILIAN NOVELS}

Wibsson Ribeiro LOPES*

UFAL

Resumo: O presente trabalho busca desenvolver uma leitura introdutória das obras Meia-noite e vinte e Noite dentro da noite, dos autores Daniel Galera e Joca Reiners Terron, respectivamente, buscando levantar questões sobre a forma romance, a alegoria nacional e o narrador na ficção brasileira da pós-modernidade, a partir de reflexões contidas na obra do crítico cultural norte-americano Fredric Jameson, em especial a sua noção de pós-modernidade. Ao final, concluímos que estas obras apresentam uma leitura sobre a subjetividade em tempos neoliberais. Acompanhando este trajeto usaremos também como apoio o trabalho do filósofo Slavoj Zizek.

Palavras-chave: Pós-modernidade. Romance brasileiro contemporâneo. Subjetividade.

Abstract: This article seek to develop an introductory reading of the novels Meia-noite $e$ vinte and Noite dentro da Noite, from the authors Daniel Galera and Joca Reiners Terron, respectively, searching to raise questions about the form-novel, the national allegory and the narrator on the Brazilian contemporary fiction of the postmodernity from the reflections contained on the work of the North American cultural critic Fredric Jameson, in special his notion of postmodernity. At the end, we conclude that this novels present a reading about the subjectivity on neoliberal times. Following this path we will use also as a support the work of the philosopher Slavoj Zizek.

Keywords: Postmodernity. Contemporary Brazilian novel. Subjectivity.

\section{Introdução}

Em sua conferência clássica, Posição do narrador no romance contemporâneo, Theodor Adorno caracterizou a situação do narrador como um paradoxo: "não se pode mais narrar, embora a forma do romance exija a narração” (ADORNO, 2003, p. 55). Desde então esse impasse parece só ter se agudizado, afastando-nos da perspectiva apresentada por Ian Watt e sua concepção de realismo focada em um narrador obediente a preceitos cartesianos e individuais (WATT, 1990).

O romance foi a forma de arte específica da era burguesa, como diz Adorno. Mas na era aberta pelo século XX, de catástrofes, desastres, traumas

\author{
* Mestre em História \\ pela Universidade \\ Federal de Alagoas. \\ E-mail:wibsson@ \\ gmail.com
}


e achatamento dos sonhos coletivos, o que resta é uma forma de arte que se vê na obrigação de lidar com os rastros e ruínas, com os fragmentos e elipses, com a erosão de todo o chão comum que parecia ter sido legado pela filosofia e pela literatura pregressa. Os romances dessa época, como Adorno sentencia, se assemelham a epopeias negativas:

São testemunhas de uma condição na qual o indivíduo liquida a si mesmo, convergindo com a situação pré-individual no modo como esta um dia pareceu endossar um mundo pleno de sentido. Essas epopeias compartilham com toda a arte contemporânea a ambiguidade dos que não se dispõem a decidir se a tendência histórica que registram é uma recaída na barbárie ou, pelo contrário, o caminho para a realização da humanidade, e alguns se sentem confortáveis demais no barbarismo. Nenhuma obra de arte que valha alguma coisa deixa de encontrar prazer na dissonância e no abandono (ADORNO, 2003, p. 62-3)

Para fora da controvérsia entre uma arte política engajada e uma arte pela arte, a conclusão de Adorno lembra que ao voltar-se para a barbárie produzida pela sociedade liberal o artista e sua obra constroem testemunhos de liberdade, mostrando aquilo que o desenvolvimento capitalista eclipsaria com o fulgor de sua imagem de progresso. Diante disso, a função de narrar não mais estaria comprometida a noções de linearidade e causalidade típicas de convenções adequadas a uma era que não mais existe, mas ressaltaria agora os rumores produzidos na carcaças da civilização.

Jaime Ginzburg tomará a conclusão de Adorno para pensar a produção literária recente no Brasil. Vendo em muitas das narrativas contemporâneas o respaldo a uma tendência de questionamento da visão patriarcalista de nossa tradição, confrontando lugares estabelecidos e abrindo espaço para novas vozes e questionamentos antagônicos ao conservadorismo vigente. A literatura brasileira contemporânea abriu espaço para vozes outrora excluídas do discurso literário, representações sobre conflitos que pareciam apagados de nossa história e problemas que foram relegados ao esquecimento (GINZBURG, 2012). Além disso, o questionamento ao sujeito cartesiano abriu o espaço para narrativas que privilegiam a descontinuidade, o fluxo de memórias livre de amarras, a destituição de lugares de privilégios e outras formas de narrar: Os textos poderiam ser interpretados, nesta perspectiva, como elaborações da História a partir de perspectivas não hegemônicas, não dominantes, que podem muitas vezes remeter a segmentos sociais tratados como minorias ou excluídos.

Pensamos haver nessa hipótese um bom indicativo para olharmos os narradores dos romances Noite dentro da noite, de Joca Reiners Terron (TERRON, 2017) e Meia-noite e vinte, de Daniel Galera (GALERA, 2016). No primeiro, um protagonista que é "narrado", por assim dizer, que tem sua história de vida relembrada, de maneira onírica, permeada de imagens que oscilam entre a fantasia e o horror traumático, por terceiros que lhe 
contam seu passado cheio de elipses, contradições e pontos inconclusos. No segundo romance, um panorama que se constrói a partir do entrelaçamento de três vozes diferentes, de pessoas na meia idade que outrora pertenceram a um mesmo grupo literário na juventude e assistem ao desmoronamento do mundo e ao caos urbano em sua cidade natal, perplexos e incapazes de qualquer intervenção digna de capacidade transformadora.

Pensamos aqui modernidade e moderno a partir das reflexões legadas por Gumbrecht e Fredric Jameson. Gumbrecht vê a modernidade como um conceito em cascata, possuindo várias significações. Moderno pode significar tanto um adjetivo que define o presente em relação ao passado e ao futuro; pode se referir à modernização epistemológica dos 1800, a qual o nome de Hegel fulgura com importância, marcado pela emergência de um observador de segunda ordem, que não deixa de realizar o movimento de se auto observar enquanto observa a realidade; pode significar o período do alto modernismo do começo do século XX, época de grandes transformações nas artes e nas literatura e pode significar o ainda confuso período chamado de pós-modernidade (GUMBRECHT, 1998). Gumbrecht propõe não escolher uma dessas definições e periodizações, mas ver a modernidade como conceitos em cascata, agrupando todas estas definições.

Acreditamos que Fredric Jameson propõe uma abordagem semelhante quando sugere ver a palavra modernus como um dêitico, um modificador [shifter] que funciona como demarcador temporal entre o agora, o antes e o depois; um sinalizador do tempo presente em relação com o novo e em demarcação com o antigo (JAMESON, 2005).

A literatura vive uma época de espectralidades: os espectros da alta literatura e do modernismo, que atormentam a construção ficcional hoje e delineiam o que chamamos precária e ainda provisoriamente de pós-modernidade; os espectros nas imagens produzidas em escala vertiginosa e avassaladora para o olho humano, despejadas na internet com uma enxurrada de informações diariamente incomensurável para o entendimento humano total; o espectro dos fantasmas de nosso passado e de nossos familiares, de nossa história e de nossas supostas identidades. É com todos esses espectros, e outros, que a literatura hoje deve lidar: “O espectro nos coloca em relação com um outro, de outro tempo, que não está presente, mas não cessa de voltar. O lugar singular a partir do qual podemos falar com ele é o da filiação, do apelo, da interpelação (PERRONE-MOISÉS, 2017, p.45).

Joca Reiners Terron e Daniel Galera lidam a seu modo com esta espectralidade. No primeiro, a ligação com a história familiar, que é uma história de fantasmas, e evolui para os fantasmas dos mortos em guerras injustas, nas torturas, nas fugas das guerras, na distorção da história; no segundo, na espectralidade de uma sociedade tomada pelo mundo virtual, pelo cálculo racional das mercadorias, pelo mercado financeiro que já colonizou cada 
palmo da vida material e onde a natureza também só é ofertada dentro da dinâmica dos valores de troca.

Acreditamos na possibilidade de que, através de uma leitura detida dos romances destes que são dois dos autores mais importantes da narrativa contemporânea brasileira, poderemos avançar a reflexão sobre modernidade, pós-modernidade e narrativa, inserindo a literatura na reflexão sobre o atual mundo de subjetividades neoliberais e predomínio das mercadorias sobre as relações humanas. Mais do que isso, procurar impulsos de utopia nestas narrativas, contribuir com o uso da imaginação como ferramenta para desbloquear este futuro que nos é dado, este imenso deserto que nos oferta sistemática e incessantemente um novo que é, rigorosamente, a mesma barbárie capitalista e liberal de sempre.

\section{Meia-noite e vinte: alegoria do hiperespaço pós-moderno}

O nosso tempo presente por vezes é descrito como uma situação de crepúsculo, de fim da história e de bloqueio de qualquer capacidade de imaginação para além do agora, uma situação de déficit de utopias e de domínio total do mercado. É como se estivéssemos na iminência de uma catástrofe, ou pior, na catástrofe de viver em um mundo onde aparentemente nada irá acontecer. Acompanhando a célebre definição de Jameson:

O pós-modernismo é o que se tem quando o processo de modernização está completo e a natureza se foi para sempre. É um mundo mais completamente humano do que o anterior, mas é um mundo no qual a 'cultura' se tornou uma verdadeira 'segunda natureza'. De fato, o que aconteceu com a cultura pode muito bem ser uma das pistas mais importantes para se detectar o pós-moderno: uma dilatação imensa de sua esfera (a esfera da mercadoria), uma aculturação do Real imensa e historicamente original, um salto quântico no que Benjamin ainda denominava a 'estetização' da realidade (ele achava que isso dava em fascismo, mas nós sabemos que é apenas divertido: uma prodigiosa alegria diante da nova ordem, uma corrida às compras, nossas 'representações' tendendo a gerar um entusiasmo e uma mudança de humor não necessariamente inspirados pelos próprios objetos representados) (JAMESON, 1997, p.13-4).

O romance "Meia-noite e vinte”, de Daniel Galera, parece dialogar com esta definição através de uma série de características que podem ser consideradas típicas não só de uma narrativa pós-modernista mas também, evocados pelos narradores, atributos de uma sociedade pós-moderna.

O romance é narrado por três personagens que se revezam ao longo dos seis capítulos da obra. Os três se conhecem e são amigos de longa data que se reencontram após a morte de Andrei, um outro amigo em comum. Os três narradores compartilham uma sensação de melancolia e de vida no fim dos tempos, em meio ao caos urbano de uma Porto Alegre com rodoviários 
em greve, um verão escaldante, a ressaca dos protestos que ficaram conhecidos como as Jornadas de Junho de 2013 e a sensação de que nada, nunca mais, irá mudar.

Assim, a personagem Aurora, já no primeiro capítulo, exprime a sensação de viver em uma “catástrofe lenta e irreversível” (GALERA, 2016), um sentimento próprio da pós-modernidade, uma sensação à qual o romance irá tentar dar vazão de diversas maneiras e que será constante na voz de todos os narradores. Aurora repetirá esse sentimento de derrocada da civilização, esse mal-estar próprio de um mundo que teve cada canto esquadrinhado pela lógica da mercadoria, dominado pelos simulacros e artefatos culturais, em uma espécie de fim, de esgotamento de qualquer capacidade criativa e elaborativa do homem, de fechar do futuro enquanto tal; já Antero, cético e irônico, verá nessa ideia de colapso civilizacional apenas mais do mesmo. Diz ele: "Os seres humanos criam esses mitos justamente porque o fim do mundo é algo que sistematicamente não acontece” (GALERA, 2016, EPUB).

A sociedade no romance se exibe às personagens como uma rede incomensurável; estas se encontram apequenadas diante da realidade do capitalismo multinacional, do caos urbano, do mundo virtual que engolfa o que era a realidade terrena. Um cenário que nos parece condizente com a definição de hiperespaço pós-moderno dada por Jameson:

...essa última mutação no espaço - o hiperespaço pós-moderno - conseguiu, por fim, transcender as capacidades do corpo humano individual de se localizar, de organizar pela percepção o seu entorno imediato e de mapear cognitivamente a sua posição em um mundo exterior mapeável. (...) essa disjunção alarmante entre o corpo e o seu meio ambiente construído - que está para o atordoamento inicial do antigo modernismo como as velocidades das naves espaciais estão para as dos automóveis - pode por si só permanecer como o símbolo do pós-modernismo, em analogia àquele dilema ainda mais grave, que é a incapacidade de nossas mentes, ao menos por enquanto, de mapear a grande rede de comunicação global, multinacional e descentralizada, na qual nos encontramos presos como sujeitos individuais (JAMESON, 2006, p. 37-8).

O romance nos parece a tentativa de representar como um microcosmo esse hiperespaço pós-moderno, reproduzindo através do cotidiano das personagens nas cidades de Porto Alegre e São Paulo sua reação ao bombardeio de imagens, ícones pop, referências, estímulos, sensações e informações. Para Jameson, a problemática da alegoria na pós-modernidade pode ser formulada como:

a questão colocada ao pensamento pela consciência de distâncias incomensuráveis no interior dos objetos desse pensamento, e como as várias respostas interpretativas ideadas para abranger fenômenos a respeito dos quais todos, pelo menos de modo geral, concordamos que nenhum tipo 
de pensamento ou de teoria isolada poderia abranger. A interpretação alegórica é, antes de mais nada, uma operação interpretativa que começa por reconhecer a impossibilidade de interpretação no sentido antigo, e por incluir essa impossibilidade em seus próprios movimentos provisórios ou até mesmo aleatórios (JAMESON, 1996, p. 184).

A alegoria é vista como uma "espécie de esquadrinhamento", uma “dialética”. No caso específico de Meia-noite e vinte, o romance intenta funcionar como uma alegoria desse hiperespaço. Cumpre notar também que a morte de Andrei, presumivelmente em um assalto, mostra que reside na violência urbana uma violenta intrusão do real, uma ansiedade de nosso tempo que a obra exprime através da inclusão deste personagem como uma fantasmagoria, que persiste por todos os capítulos; um lembrete da decomposição necessária dos corpos, da decadência da natureza, de uma temporalidade que ainda persiste mesmo além dessa era em que a própria cultura nos aparece como uma segunda natureza.

Mais do que explorar com minúcia cada um dos pontos abertos, e são inúmeros, o romance parece apenas buscar na voz dos narradores ganchos para exibi-los, dispô-los na mesa como peças jogadas sem muito aprofundamento. Reflexões sobre a situação da mulher, guiadas pela personagem Aurora, sobre a questão do aborto, sobre o assédio nos locais de estudo e trabalho, sobre a pornografia na era digital. Ganchos abertos por Emiliano, um homossexual envolvido em jogos de virilidade e violência com seus pretensos parceiros, um jornalista que se vê, por necessidades de mercado, na necessidade de biografar o recém-falecido amigo escritor, explicitando a lógica do espetáculo que já devassou há muito tempo o mundo da literatura; também as diversas problemáticas abertas por Antero, talvez o mais paradigmático dos três personagens, um cínico palestrante de eventos motivacionais e publicitários que se utiliza de teorias outrora subversivas e críticas, de Deleuze a Sade, para vender produtos e serviços; tipo que encarna como ninguém o lema "eles sabem o que fazem, mas o fazem mesmo assim" (ZIZEK, 1996). Uma autêntica subjetividade neoliberal, que trabalha por meio de quantificações constantes, chegando mesmo a atravessar uma manifestação de massas inicialmente com o intuito de entender a mentalidade dos participantes, seus consumidores em potencial. Emiliano o descreve nos seguintes termos: "sua existência, aos meus olhos, se aproximava de um esquete de humor absurdo que não tinha hora pra terminar nem reconhecia diferença entre palco e vida. Se fosse proposital, seria genial. Talvez fosse. Ninguém poderia ter certeza (GALERA, 2016).

Nessa descrição vemos em Antero o produto do próprio sujeito neoliberal, tanto entendido como empresa de si, como um sujeito engolfado pela própria performance auto-irônica, o seu eu não passando de uma imagem especulativa, imerso em uma performance constante. Postura que é condizente com o novo espírito do capitalismo, não mais austero e reservado como nos 
primórdios de sua evolução, mas conclamando a massa de consumidores a um gozo imperativo e incessante.

Pairando na narrativa está o fantasma de Andrei, o escritor morto, futuro biografado de Emiliano. A partir de sua morte abrem-se discussões sobre a literatura na pós-modernidade, a relação do escritor com seu público, quase como uma celebridade.

Em meio a isso, discussões sobre o antropoceno, a ausência de futuro, e a tentativa de adentrar no anonimato em um mundo que não parece mais permitir escapatória aos escritores, nem a ninguém, quando a internet deixou de ser vista como um “comum” e foi engolfada pela lógica de cerceamento do capital. Contudo, talvez ainda que muito mais cerceada pelas agências publicitárias e pela propaganda, a tecnologia parece ocupar um papel frente à arte e à literatura, como um elemento incontornável que vem moldando a percepção das relações, comportamentos e a recepção da criação estética, modificações que se dão, na verdade, em inúmeros níveis de linguagem.

Como dito, mais do que explorar cada uma dessas inúmeras questões, o que parece é que o romance busca fazer um precário mapeamento cognitivo da incomensurabilidade pós-moderna sem se deter ou explorar com minúcia cada um desses aspectos. Parece ser esta a forma pela qual o romance tenta dar conta de uma realidade inapreensível pelos sujeitos individuais. Cumpre notar ainda que os narradores parecem seguir a lógica aceleracionista pela qual são afetados, e o próprio romance dispõe suas questões de maneira quase displicente, em uma metodologia associativa típica do pós-modernismo.

Por trás de tudo, algumas questões maiores parecem estar abertas para a análise crítica: a dimensão utópica que parece ainda assim existir, por exemplo, na imagem do veado branco dos pampas, oriunda do manual de criptozoologia de Aurora, um espécime raro que parece representar a existência de uma área natural ainda livre do domínio do cálculo humano, uma zona aberta ao contingente e ao acaso em um mundo neoliberal onde tudo parece ter sido esquadrinhado e controlado. Parece como uma recompensa a Aurora, que, no final do romance, decide retornar ao sítio no qual passou a virada do ano novo de 1999 para 2000 com os amigos do zine orangotangos e finalmente encontra o espécime raro:

$\mathrm{O}$ veado se afastou de mim sem nenhuma pressa. O branco foi se apagando no breu da mata nativa até sumir. Fiquei um instante indecisa. Segui na direção que ele havia percorrido, tentando refazer seus passos, mas não voltei a avistá-lo. Ele tinha descido para o fundo do vale, lá onde a mata se adensava ainda mais (GALERA, 2016, EPUB).

A maneira como a política e a criação revolucionária parecem estar bloqueadas por uma lógica capitalista que afeta todas as personagens, elas próprias nos parecendo modelos mais ou menos típicos de sujeitos neoliberais, também nos sugere um caminho para a reflexão, visto que residem 
aqui os maiores sinais do fenômeno da reificação e das limitações impostas ao sujeito na pós-modernidade.

\section{Noite dentro da noite: o Sujeito pós-traumático}

Pensamos que estes problemas podem ser colocados ao lado de outros que emanam do romance Noite dentro da noite, de Joca Reiners Terron. É difícil construir um resumo sintético e ao mesmo tempo sólido sobre a obra. Trata-se de uma narrativa moldada a partir de afirmações provisórias, inconclusas, permeado de incertezas. Parte de sua estranheza está nas repetições, reiterações e alterações leves dos eventos narrativos que produzem rimas obscuras com a história do Brasil, da América Latina e da Alemanha nazista. Seguimos aqui alguns apontamentos dados por Holdefer como possibilidade de leitura da obra, mas extrapolando algumas de suas hipóteses:

Da forma como está estruturado, Noite dentro da noite assume quatro aspectos, nenhum deles independente dos outros três. São gêneros, estilos e temáticas -- que em geral se repelem ou se anulam, e que se tornam incongruentes quando postos lado a lado -- a partir dos quais é possível examinar ou definir o novo trabalho de Joca Reiners Terron. O subtítulo irônico sugere que estamos diante de uma autobiografia. O caráter onírico, com um acúmulo de imagens que parecem saídas de um inconsciente transtornado, aponta para um romance de inspiração surrealista. Os diferentes relatos que resgatam a trajetória e as lendas dos Reiners compõem uma saga familiar. Por fim, o crescimento gradual de um protagonista estabelece as bases de um romance de formação peculiar (HOLDEFER, 2017).

A personagem que nos é apresentada no primeiro capítulo, intitulado A história do esquecimento, é tratada apenas por você, um garoto que ouve a história narrada por um homem que se apresenta como Curt Meyer-Clason. O romance se desdobrará a partir dessa narração em segunda pessoa, contando aos poucos a história desse garoto misterioso que perdeu a memória em uma brincadeira de esconde esconde, no ano de 1975, em plena ditadura militar no Brasil, um ano pitoresco no qual nevou na cidade de Medianeiras no Paraná, o Ano do Grande Branco.

“Na manhã daquele dia você deixou de ser você, nem sequer tinha completado doze anos e passou a ser outra pessoa” (TERRON, 2017, p.16). Sem memória, este garoto, que ocupa a mesma posição que nós, os leitores do romance que recebemos a enxurrada de informações obscuras e desencontradas, construirá aos poucos, a partir do que lhe é dito, informações que lhe oferecem uma fraca noção de eu. O romance constrói, página após página, também com muito de um esforço fragmentado e confuso, uma subjetividade estilhaçada, que parece imergir de um poço no qual ficou enclausurada por muito tempo. Como diz Curt Meyer-Clason: "Esta história 
é sobre você, porém é como se a assistisse em um filme cujo ator principal é desconhecido” (TERRON, 2017, p.13)

Não lembrar muito bem de uma infância no período militar é não lembrar do próprio período militar; não lembrar do irmão misterioso, que parece desaparecido; estranhar a própria mãe, a chamada rata, vista com desconfiança porque parece mentir o tempo todo; não entender a postura dos pais e tios, descendentes de alemão, sempre armados, desconfiados, às vezes feridos, preparados para a fuga; fugas que acontecem todo o tempo fugindo de um perseguidor que não tem rosto ou nome ou explicação. Esta relação entre memória, história e esquecimento instauram problemas envolvendo a própria noção de identidade: a família do garoto lhe é estranha, a nação do garoto lhe é estranha e mesmo sua história pessoal, sua vida, os lugares onde viveu. Ele não possui passado definido, muda-se sem deixar rastros, abandonando velhos brinquedos, não sente nada ao cantar o hino nacional. Não se identifica com sua história, com seus parentes, com seu país. "Quem é você”, são as palavras com as quais se fecha o primeiro capítulo.

A partir daí terá início apenas um maior aprofundamento na confusão e na loucura. Capítulo após capítulo elementos como uma alga misteriosa, a presença de indígenas com remédios obscuros, centros de experimentação nazista, locais onde crianças são confinadas na ditadura, a casa do sol, onde vivia a poeta Hilda Hilst, tudo isso é inserido na trama como a constituir imagens que deem conta desse sujeito sem capacidade sequer de voz própria dentro do romance.

Posteriormente, Noite dentro da noite acompanhará este garoto em sua vida adulta, na transição da ditadura para o período pós-democrático, cursando arquitetura em uma universidade e se envolvendo com militares e com atentados contra manifestantes de esquerda. Em paralelo, a história narrada de personagens envolvidos com experimentos nazistas e campos de prisioneiros durante a II Guerra Mundial, além de muitas outras subtramas.

Algumas questões podem se apresentar como chaves de leitura interessantes para a obra. Poderíamos estar diante de mais uma alegoria nacional, um romance que pensa a identidade do país, como outros clássicos nacionais o fizeram? Se levarmos em conta a polêmica definição de Jameson:

Todos os textos do terceiro mundo são necessariamente, quero argumentar, alegóricos, e de um modo muito específico: eles estão para ser lidos como o que eu vou chamar de alegorias nacionais, mesmo quando, ou talvez eu deva dizer, particularmente quando suas formas se desenvolvem predominantemente de mecanismos ocidentais de representação, tais como a novela (JAMESON, 1986, p. 66, nossa tradução).

A citação apresentada despertou polêmicas: foi acusada de simplista e eurocêntrica. Pensamos, contudo, que a hipótese pode ser explorada se lida como uma tendência, um procedimento comum em romances 
latino-americanos. Sendo assim, nos propomos a ler Noite dentro da noite como uma possível alegoria nacional. Mas é claro que aqui, no caso da narrativa de Joca Reiners Terron, onde tudo está embaralhado, esta questão não pode ser instaurada de maneira corriqueira. A região de Curva de Rio Sujo, onde está o protagonista e sua família, é, sintomaticamente, uma região de fronteira, indefinida entre o Brasil e o Paraguai. Longe de significar um descarte da problemática da nação, pensamos que esta aparente rejeição, dentro da obra, da questão nacional, é a forma com a qual esse problema está posicionado. Outra prova disso é a presença da Guerra do Paraguai como um interesse constante de leituras do menino, uma Guerra que significou a humilhação da nação paraguaia e uma vitória que consolidou a imagem de nação de Brasil e a formação de nosso exército, um evento que viria a se somar a outros que daria corpo à proclamação da república, em anos vindouros, fundamental no imaginário de nação do Brasil. Todos esses problemas ao invés de impossibilitar a leitura da alegoria em uma chave nacional podem indicar as transformações que a noção sofreu durante a pós-modernidade e a forma como o romance lida com isto.

Noite dentro da Noite também pode ser visto como um romance de formação? Sim, se levarmos em conta que a primeira pessoa, usual nesse tipo de narrativa, é descartada e é posta em seu lugar a ideia de um sujeito que aprende e constrói uma ideia de si mesmo a partir de definições dadas por um outro, o personagem Curt Meyer-Clason.

Talvez seja o caso de pensar que o sujeito descentrado, aparentemente vazio, que é “montado” em Noite dentro da noite não é um sujeito atípico, fora do usual, mas uma imagem perfeitamente cabível para dar conta da formação da subjetividade tal qual ela é, um sujeito que é, para falar com Zizek e Lacan, “um nada, um vazio que existe”. (ZIZEK, 2008, p.104)

Acreditamos ser possível estabelecer através da leitura de Noite dentro da noite uma discussão presente em Zizek a partir de suas leituras de Lacan e Hegel. A passagem a seguir é lembrada pelo autor esloveno para definir a chamada noite do mundo hegeliana, a emergência da subjetividade:

O ser humano é essa noite, esse nada vazio, que contém tudo em sua simplicidade - uma riqueza infinita de representações, de imagens, das quais nenhuma lhe pertence - ou que não estão presentes. Essa noite, a interioridade da Natureza que existe aqui - o Eu puro - em representações fantasmagóricas, é noite à sua volta; surge então uma cabeça ensanguentada aqui - mais adiante, outra aparição branca, e elas desaparecem também de repente. É essa noite que se percebe quando se olha um ser humano bem nos olhos: uma noite que se torna terrível (ZIZEK, 2017, p. 89-90).

Para além da ressonância do substantivo noite da ideia hegeliana, presente no título do romance, é interessante pensar se essa queda do Eu na loucura e a saída para a normalidade, esta inversão da ideia iluminista de 
uma luz da razão rumo a uma ideia na qual o sujeito se define após a saída do abismo e sua construção simbólica da realidade pode nos ser útil para pensar este estranho protagonista passivo do romance Noite dentro da noite e o que ele pode nos indicar à reflexão.

O protagonista do romance é submetido a múltiplas versões de interferências externas, de ordem histórica, de ordem interior e mesmo formas de exclusão, como as violências a que é submetido na escola pelos valentões filhos de militares. Pensamos que tamanha é a quantidade de traumas a que este personagem foi submetido que podemos estabelecer um diálogo entre ele e o que Zizek define como sujeito pós-traumático:

Um sujeito pós-traumático é, desse modo, uma vítima que, por assim dizer, sobrevive à própria morte. Todas as diferentes formas de encontros traumáticos, independentemente de sua natureza específica (social, natural, biológica, simbólica), levam ao mesmo resultado: surge um novo sujeito que sobrevive à morte (revogação) de sua identidade simbólica. Não há continuidade entre esse novo sujeito pós-traumático (digamos, a vítima de Alzheimer) e sua antiga identidade: depois do choque, surge literalmente um novo sujeito. Suas características são bem conhecidas a partir de numerosas descrições: falta de envolvimento emocional, indiferença e alheamento profundos; é um sujeito que não está mais 'no mundo' no sentido heideggeriano de uma existência encarnada. $O$ sujeito vive a morte como forma de vida (ZIZEK, 2017, p. 92).

Não temos acesso a uma narrativa confiável da vida desse sujeito. O que lemos apenas é aquilo contado por Curt Meyer-Clason. Mas justamente esse procedimento é que abre caminho para esta leitura de um sujeito pós-traumático. Sua indiferença frente ao texto é tamanha que outra pessoa conta-lhe sua vida. Por outro lado, o que se narra parece ser a própria reconstituição simbólica desse novo sujeito, após as sucessivas experiências traumáticas, de diversas ordens. Nos questionamos então se não haveria na construção desse personagem tão atípico uma abertura para o debate com forma como a subjetividade é vista na sociologia crítica contemporânea e na filosofia, bem como uma possibilidade de debate com a nossa História nacional.

\section{Considerações finais}

Acreditamos que a leitura dos romances aqui apresentados, posta lado a lado com a teoria de Fredric Jameson, oferecem bons indicativos da situação sócio-cultural que foi definida como pós-modernidade. Para além de todas as críticas que recebeu nas últimas décadas, pensamos que a ideia de encarar a pós-modernidade como uma dominante cultural ainda é capaz de fornecer boas perspectivas de análise e problematizar aspectos da 
literatura e da produção cultural de nosso tempo. É o que acreditamos ter modestamente apresentado neste trabalho.

Todas as problemáticas levantadas nos apontam para problemas que não refletem questões isoladas apenas na obra, mas preocupações concernentes ao fazer literário em uma época de crises e ruínas que se acumulam, de tragédias sociais e traumas que se avolumam. Os narradores, cada um a seu modo, perseguem dimensões semelhantes. Os narradores de Meia-noite e vinte, de Daniel Galera, estão às voltas com a sociedade hiperconectada e informacional, onde a cultura, a política e a economia se fundiram e tornaram-se um grande ente capaz de engolfar todas as subjetividades. Cada um a seu modo, estes narradores vão buscar alternativas a esta sociedade regulada por multinacionais e onde os sonhos e utopias não mais parecem fazer sentido e as ambições de juventude não cabem mais, ao mesmo tempo que se veem às voltas com o espectro do amigo morto e a ansiedade provocada pela violência urbana nas grandes cidades. Por outro lado, o romance Noite dentro da Noite oferece uma saída formal interessante ao constituir sua história a partir de uma narrativa quase toda guiada por vozes outras que não a do presumível protagonista, uma narração em segunda pessoa que toma conta dos capítulos e constrói a imagem de um sujeito passivo, ou apassivado, reinserido em um universo simbólico ao qual não parece familiarizado, ao contrário, parece atordoado e em estado de paralisia. A narrativa funcionaria assim como uma alegoria nacional, como uma forma que pensa também os sucessivos traumas históricos pelos quais passou o Brasil ao longo de séculos, em uma dialética entre esquecimento e memória que parecem ainda longe de se encerrar.

Diante do exposto, concluímos que a relação entre neoliberalismo e cultura, entre pós-modernidade e literatura ainda merecem uma exploração mais detida em nossa ficção contemporânea. Olhar para os romances da última década sob a ótica das transformações pelas quais passou o Brasil e o mundo nos parece salutar. Difícil seria imaginar que a literatura sairia incólume dos embates políticos atrozes que aconteceram e seguem em aberto.

\section{Referências}

ADORNO, Theodor. Notas de literatura I. Tradução Jorge M.B. de Almeida. São Paulo: Duas cidades; Ed.34, 2003.

BENJAMIN, Walter. Baudelaire e a modernidade. Tradução João Barrento. Belo Horizonte: Editora Autêntica, 2015.

Magia e técnica, arte e política: Ensaios sobre literatura e história da cultura. Obras escolhidas Volume 1. Tradução Sérgio Paulo Rouanet. São Paulo: Editora Brasiliense, 1985.

GALERA, Daniel. Meia-noite e vinte. São Paulo: Companhia das Letras, 2016. 
GINZBURG, Jaime. O narrador na literatura brasileira contemporânea. Tintas. Quaderni di letterature iberiche e iberoamericane, n. 2, pp. 199221, 2012. Disponível em: http://riviste.unimi.it/index.php/tintas2012. Acesso em: 23 ago 2017.

GUMBRECHT, Hans Ulric. Modernização dos sentidos. São Paulo: Editora 34, 1998.

JAMESON, Fredric. A virada cultural: reflexões sobre o pós-modernismo. Tradução Carolina Araújo. Rio de Janeiro: Civilização Brasileira, 2006.

Modernidade singular. Tradução Roberto Franco Valente. Rio de janeiro: Civilização Brasileira, 2005.

. As sementes do tempo. Tradução José Rubens Siqueira. São Paulo: Editora Ática, 1997.

Pós-modernismo, a lógica cultural do capitalismo tardio. Tradução Maria Elisa Cevasco. São Paulo: Editora Ática, 1997.

. O Marxismo Tardio. Adorno ou a persistência da dialética. São Paulo: UNESP, 1996.

. Third-World Literature in the Era of Multinational Capitalism. Social Text, n. 15, pp. 65-88, 1986. Disponível em: http://www.jstor.org/ stable/466493. Acesso em: 23 ago. 2017.

PERRONE-MOISÉS, Leyla. Mutações da literatura no século XXI. São Paulo: Companhia das Letras, 2016.

SCHWARZ, Roberto. Um mestre na periferia do capitalismo: Machado de Assis. São Paulo: Duas cidades; Editora 34, 2000.

TERRON, Joca Reiners. Noite dentro da noite. São Paulo: Companhia das Letras, 2017.

ZIZEK, Slavoj. Acontecimento: uma viagem filosófica através de um conceito. Tradução Carlos Alberto Medeiros. Rio de Janeiro: Zahar, 2017.

. Órgãos sem corpo: Deleuze e consequências. Tradução Manuela Assad Gómez. Rio de Janeiro: Cia de Freud, 2008.

O sujeito incômodo: o centro ausente da ontologia política. Tradução Luigi Barichello. São Paulo: Boitempo, 2016.

(Org.). Um mapa da ideologia. Tradução Vera Ribeiro. Rio de Janeiro: Contraponto, 1996.

WATT, Ian. A ascensão do romance. São Paulo: Companhia das Letras, 1990.

Recebido em setembro/2017.

Aceito em novembro /2017. 